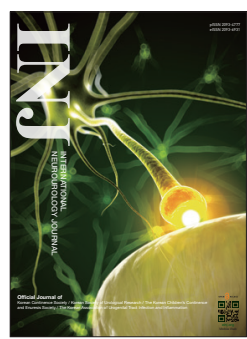

\title{
Rescue of Heart Failure by Mitochondrial Recovery
}

\author{
Jubert Marquez, Sung Ryul Lee, Nari Kim, Jin Han \\ National Research Laboratory for Mitochondrial Signaling, Department of Physiology, Department of Health Sciences and Technology, BK21 Project Team, \\ College of Medicine, Cardiovascular and Metabolic Disease Center, Inje University, Busan, Korea
}

Heart failure (HF) is a multifactorial disease brought about by numerous, and oftentimes complex, etiological mechanisms. Although well studied, HF continues to affect millions of people worldwide and current treatments can only prevent further progression of HF. Mitochondria undoubtedly play an important role in the progression of HF, and numerous studies have highlighted mitochondrial components that contribute to HF. This review presents an overview of the role of mitochondrial biogenesis, mitochondrial oxidative stress, and mitochondrial permeability transition pore in HF, discusses ongoing studies that attempt to address the disease through mitochondrial targeting, and provides an insight on how these studies can affect future research on $\mathrm{HF}$ treatment.

Keywords: Mitochondria; Heart Failure; Oxidative Stress; Protein Processing, Post-Translational; Mitochondrial Permeability Transition Pore

- Grant/Fund Support: This work was supported by the National Research Foundation of Korea (NRF) and the Korean government (MSIP) (2010-0020224, 2015R1A2A1A13001900, and 2011-0028925).

- Conflict of Interest: No potential conflict of interest relevant to this article was reported.

\section{INTRODUCTION}

Heart failure (HF) is a multicomponent disease wherein the heart is unable to provide sufficient oxygen-rich blood for the metabolic needs of the surrounding tissues. Recent technological and pharmacological trends have helped in decreasing mortalities due to HF, however, the disease still poses danger to about 5.8 million people in the United States alone, in addition to 23 million more people worldwide [1]. The Framingham Heart Study approximates 1-month to 1-year mortality at around 20\%-30\%, and 5-year mortality between 45\%-60\% [2]. It should be kept in mind that HF is a rather complex syndrome, whose progression depends on factors such as physiological conditions, preexisting cardiovascular diseases like coro- nary heart disease (CHD), high blood pressure, and diabetes; and occurs together with diseases that further aggravate the condition, such as diabetes and hypertension [3]. CHD alone, specifically coronary artery disease, was responsible for $65 \%$ of patients afflicted with HF [4]. It has also been suggested that neurological dysfunction further contributes to the progression of CHD. CHD has been directly linked with bladder pain syndrome/interstitial cystitis, a recurring discomfort around the pelvic and bladder area, wherein it was concluded that endothelial dysfunction might be a pathogenic factor common between the two conditions [5]. The pathomechanism remains unclear; however, the progression and coexistence of these diseases, which lead to HF, might be linked with mitochondrial irregularities.
Corresponding author: Jin Han (iD http://orcid.org/0000-0003-2847-0197 National Research Laboratory for Mitochondrial Signaling, Department of Physiology, Department of Health Sciences and Technology, BK21 Project Team, College of Medicine, Cardiovascular and Metabolic Disease Center, Inje University, 75 Bokji-ro, Busanjin-gu, Busan 47392, Korea

E-mail: phyhanj@inje.ac.kr / Tel: +82-51-890-6727 / Fax: +82-51-894-5714

Submitted: March 14, 2016 / Accepted after revision: March 17, 2016 


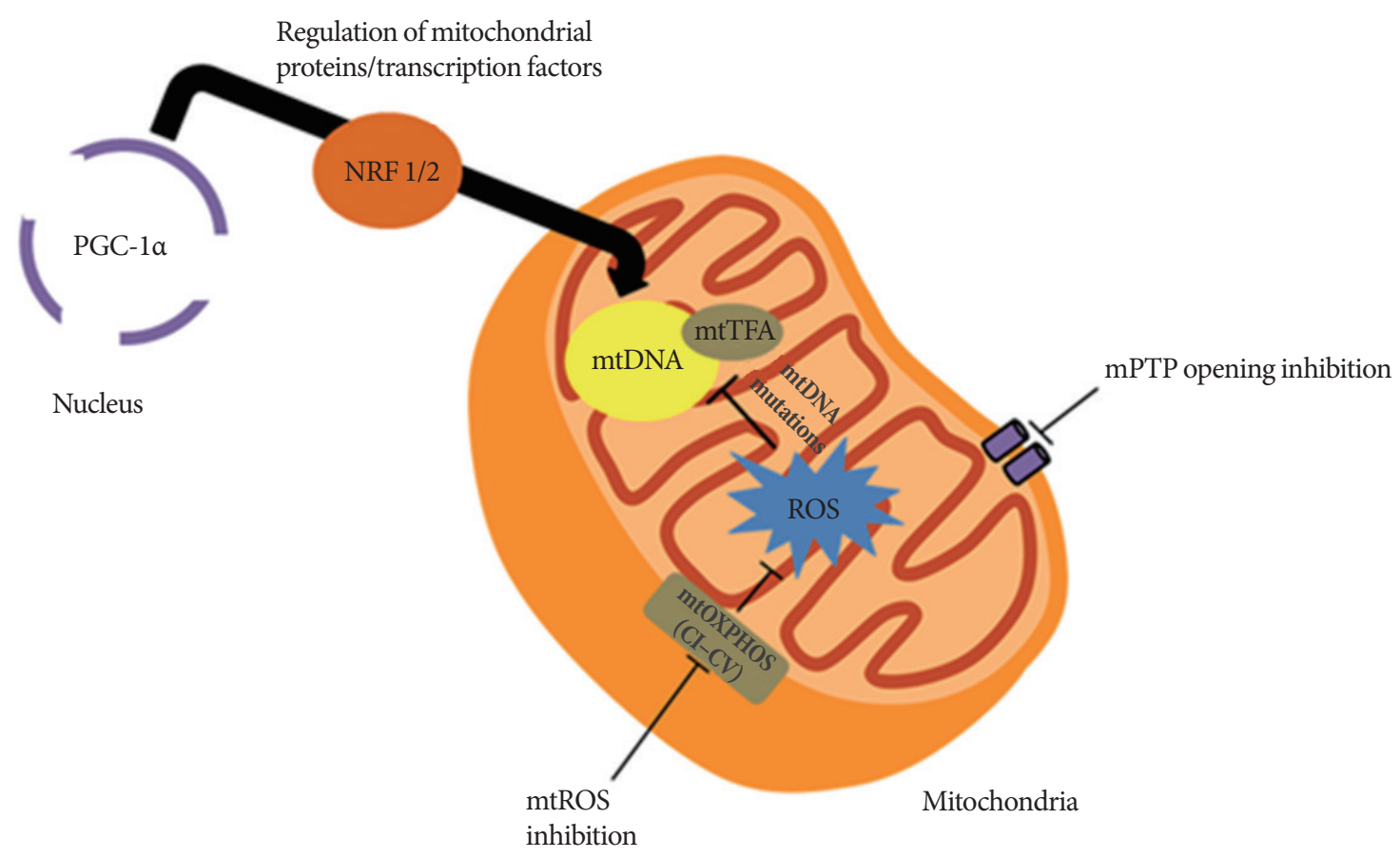

Fig. 1. Selected examples of current methods in mitochondrial targeting. Peroxisome proliferator-activated receptor gamma coactivator $1 \alpha$ (PGC-1 $\alpha$ ), which is considered a master regulator of mitochondrial proteins and transcription factors, affects the expression of mitochondrial (mt)DNA. Inhibition of mitochondrial reactive oxygen species (ROS) prevents damage to the mtDNA, decreasing the possibility of mutations. Opening of the mitochondrial permeability transition pore (mPTP) increases mitochondrial membrane permeability, causing further depolarization of the mitochondria, resulting in the loss of membrane potential. When this occurs, adenosine triphosphate production is severely affected and causes the heart to fail; thus the need to inhibit mPTP opening. CI-CV, complexes I-V of the mitochondria; mtOXPHOS, mitochondrial oxidative phosphorylation; NRF 1/2, nuclear respiratory factor 1/2; mtTFA, mitochondrial transcription factor $\mathrm{A}$.

The pervasiveness of HF is due, in part, to factors such as irregularities in signal transduction pathways and mitochondrial deterioration [6]. The role of mitochondria in the production of adenosine triphosphate (ATP) and in the regulation of cell death makes it vital for cell survival. Data published in recent years suggest that mitochondria might be pivotal in HF development [7]. The levels of oxidative stress brought about by reactive oxygen species (ROS) as well as regulation of opening/ closing of the mitochondrial permeability transition pore (mPTP) also contribute to HF development. Previous studies have implicated altered mitochondrial biogenesis as one of the causal mechanisms of oxidative phosphorylation (OXPHOS) dysfunction in cardiac remodeling [8]. It will be important to focus on restoring contractile function in failing hearts by targeting the mitochondria. This review outlines some common and recent modes of mitochondrial targeting for HF, and provides insights on future directions for HF treatment (Fig. 1).

\section{MITOCHONDRIAL TARGETS}

\section{Mitochondrial Biogenesis}

Primary alterations in mitochondrial biogenesis may be associated with the progression of cardiac pathologies. Mitochondrial DNA (mtDNA) copy number and mitochondrial content are significantly reduced in both human and rat models of failing myocardium, which can be attributed to downregulation of the mitochondrial biogenesis signaling pathways [9-12]. It is suggested that a disturbance in mitochondrial biogenesis occurs at early onset of HF, which is cardioprotective upon reversal. Recently, peroxisome proliferator-activated receptor gamma coactivator $1 \alpha$ (PGC-1 $\alpha$ ) has been studied for its central role in the regulation of transcription factors in the mitochondria, such as nuclear respiratory factor $1 / 2$ (NRF 1/2) and mitochondrial transcription factor A (mtTFA). PGC-1 $\alpha$ is a protein encoded in the nucleus and is activated during periods of high 
energy demand, such as those during increased cardiac workload, physical training or exercise, or starvation. PGC-1a is responsible for the activation of mitochondrial proliferation through its intercommunication with different transcription factors. PGC- $1 a$ was evidently decreased in various HF experimental models, and this affected essential, related transcription factors, as evidenced by decreased NRF 1/2 and mtTFA expression $[13,14]$. Targeted mtTFA disruption in cardiac tissue affected electron transport chain (ETC) capacity, eventually resulting in spontaneous cardiomyopathy and $\operatorname{HF}[15,16]$.

Increased mtDNA and mitochondrial proliferation with myofibril displacement is associated with primary mitochondrial defects and cardiomyopathy, and commonly related with increased mitochondrial biogenesis-related gene expression [17]. It was previously observed that mitochondrial proliferation was higher in cardiomyopathic murine models, and associated with the removal of adenine nucleotide translocase 1 (ANT1) [18], manganese superoxide dismutase (Mn-SOD) [19], and mtTFA [20]. Furthermore, there was increased mitochondrial mass in mtTFA-knocked out mice; in addition to decreased levels of mtDNA and cytochrome coxidase subunit I, peroxisome proliferator-activated receptors $\alpha$ (PPARa), and PPARa-dependent transcripts; and dysfunctional ETC [21]. The significant decrease in ATP revealed that increase in mitochondrial number is not enough to compensate for damage in the mitochondria. These examples demonstrate the importance of improved mitochondrial biogenesis and mtDNA copy number in cardioprotection against HF.

Recent studies have focused on targeting the mitochondria and improving mitochondrial biogenesis through various methods, including those involving pharmacological agents. Currently, there are no pharmacologic agents that specifically target mitochondrial biogenesis in HF. However, stimulation of mitochondrial biogenesis, leading to its beneficial effects, is accelerated by targeting other components such as endothelial nitric oxide synthase, adenosine monophosphate-activated kinase, and other mitochondrial biogenesis pathways, which all hold promise in addressing the disease [22,23]. A summary of some common and recent experimental and clinical interventions are presented in Table 1. One of the earlier drugs to be used, an angiotensin-converting enzyme (ACE) inhibitor named captopril (now marketed as Capoten), increased mitochondrial content in canine hearts after coronary ligation [24]. This indicates that the favorable effects may, in part, be related to mitochondrial invigoration. Current studies have examined

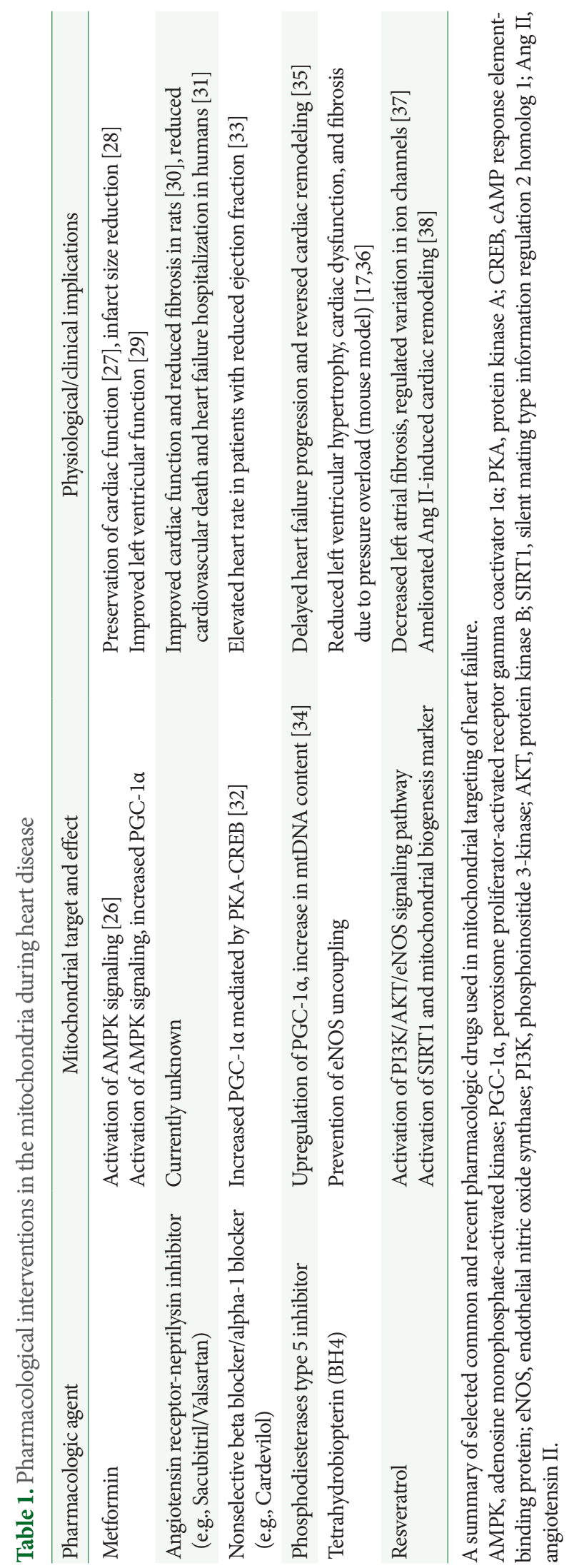

www.einj.org 
the effects of various ACE inhibitors in human patients, including that of captopril. Although captopril is widely used, patients treated with the drug presented higher incidence of coughing, and it was suggested that enalapril is more potent, owing to its effect on ejection fraction, stroke volume, and mean arterial pressure [25].

\section{Mitochondrial Oxidative Stress}

Mitochondrial oxidative stress, caused by either ROS overproduction or decreased endogenous antioxidant defenses, has been implicated in the structural and functional alterations during myocardial failure [39]. Sources of ROS in the failing heart include mitochondrial ETC, nicotinamide adenine dinucleotide phosphate oxidases, nitric oxide synthases, and xanthine oxidase [40]. The change in oxidative stress levels may contribute to changes in the abundance and copy number of mitochondria, and in the integrity of mtDNA in human cells during pathological conditions [41]. ROS may act within a threshold to generate stress responses through various cellular processes, such as modifications in specific nuclear genes, in order to maintain energy metabolism and production [42]. Decreased mitochondrial biogenesis occurs during insignificant increases in oxidative stress, in addition to increased mitochondrial DNA mutations, which eventually lead to impaired OXPHOS and cardiomyopathy. On the other hand, induction of PGC-1 $\alpha$, mitochondrial biogenesis, and enzymes related to metabolism were observed during marked elevation in oxidative stress [43].

The complex role of ROS in the progression of HF remains to be clarified. A suggested mechanism involves impairment of cellular and mitochondrial structures, such as excitation-contraction coupling proteins, which affect the mechanical function of the heart [44]. Considering that majority of the ROS originates in the mitochondria during HF, it is not surprising that these organelles are the most susceptible to oxidative damage. In fact, mtDNA is more prone to ROS damage since it lacks histones, which can serve as protection from ROS attack. This renders the mtDNA to a less efficient DNA repair system, which results in mtDNA gene mutations. Furthermore, decrease in PGC-1 $\alpha$ in affected hearts aggravates oxidative stress and mitochondrial damage, owing to the protein's role in maintaining mitochondrial antioxidant defenses [43]. ROS also regulates signaling cascades such as those involving protein kinase $\mathrm{C}$ (PKC), mitogen-activated protein kinase (MAPK), Jun Nterminal kinase, and Ras - all implicated in hypertrophy [45].
Further, ROS facilitates extracellular matrix remodeling by promoting matrix metalloproteinases either directly via posttranslational modifications (PTMs) or indirectly via nuclear factor $\kappa B(N F \kappa B)$ pathway [46]. The aforementioned roles of ROS highlight its importance and novelty as a therapeutic target for treating HF. As mentioned in the previous section, therapies involving ACE inhibitors and angiotensin II receptor blockers have been used experimentally, owing to the agents' antioxidant properties. However, it is unclear whether these agents target mitochondrial ROS directly or indirectly $[47,48]$.

Numerous studies have focused on oxidative-stress targets or energetics in HF models. Large randomized trials of antioxidant vitamins such as vitamin $\mathrm{E}$ have so far been futile, which might be due to the nonspecific nature of the vitamins, possibly inhibiting both the beneficial and negative effects of ROS. Nevertheless, it has been shown that mitochondrial targeting of ROS-scavenging molecules is protective. Modulation of substrate utilization with drugs such as perhexiline to increase myocardial energy production has only been performed in small-scale clinical studies [49]. A two-pronged approach of addressing oxidative stress and mitochondrial dysfunction together has been deemed a more efficient approach. The use of antioxidants such as triphenylphosphonium conjugation (MitoQ) and novel Mn-SOD, or catalase analogues could be considered in future HF studies.

\section{Mitochondrial Permeability Transition Pore}

Decreased energy metabolism due to dysfunction in mitochondria is further aggravated by ROS generation, which, when taken together with $\mathrm{Ca}^{2+}$ mishandling, favors $\mathrm{mPTP}$ opening. $\mathrm{mPTP}$ is a nonselective pore in the inner mitochondrial membrane, activated under high $\mathrm{Ca}^{2+}$ and ROS levels, resulting in mitochondrial dysfunction and inhibition of OXPHOS [50,51]. It was earlier thought that the inner-membrane ANT [52], outer-membrane voltage-dependent anion channel [53], and inner phosphate carrier [54] all play essential roles in MPTP induction. However, recent studies have pointed out that these components only play a supporting, regulatory role, while more compelling evidence points at the importance of matrix protein cyclophilin D (CyP-D) and mitochondrial ATPase in mPTP structure and regulation [55]. Determining the structure of mPTP would aid the development of better methods to inhibit mPTP opening, helping in the maintenance of inner-membrane integrity and preservation of ATP production, which would prevent cell death during the onset of HF. 
mPTP is widely studied in cardiac pathology, including ischemia/reperfusion (I/R) and HF. It was earlier observed that inhibition of mPTP opening by cyclosporine A (CsA) offers possible cardioprotection. Subsequent research in a myocyte model of hypoxia/reoxygenation found that CsA is a potent inhibitor of mPTP pore in isolated mitochondria. Earlier studies involving CsA also revealed cardioprotection from reoxygenation injury in isolated cardiac myocytes [56]. This was supported by another study where CsA exhibited cardioprotection from reperfusion injury in the Langendorff perfused heart [57]. Cardioprotective effects of CsA were also observed in CyP-D-knocked out mice, exhibiting a significant reduction in infarct size in an $\mathrm{I} / \mathrm{R}$ model [58]. However, owing to its affinity to cytosolic cyclophilin-A, CsA poses a problem regarding cardioprotection, wherein it inhibits calcineurin, which directly affects heart function [59] and is reported to possess immunosuppressive activity [60]. In order to address such problems exhibited by CsA, analogues have been developed that are inactive against calcineurin, but still bind strongly to CyP-D. The cardioprotective properties of these analogues are similar to that of CsA, and are potent even when administered only during early reperfusion [61-64].

Several other indirect inhibition methods for MPTP have been suggested, mostly focused on reduction of mitochondrial build-up of pore-formation inducers such as ROS and $\mathrm{Ca}^{2+}$. Considering that oxidative stress is a robust $\mathrm{mPTP}$-opening activator, clinical use of ROS scavengers might be effective [65]. Propofol, which is used during cardiac surgeries, inhibited mPTP opening in an I/R model of isolated rat hearts, exhibiting significant post-ischemic recovery of heart function. This cardioprotective effect could be attributed to propofol's role in inhibiting the formation of ROS-cardiolipin complexes in the respiratory chain by maintaining the integrity of cardiolipin under ROS attack [66]. In another case, 3-Methyl-1-phenyl-2-pyrazolin-5-one (MCI-186) significantly decreased myocardial infarction size and inhibited $\mathrm{mPTP}$ opening in an $\mathrm{I} / \mathrm{R}$ rat model. This effect could be attributed to the action of MCI-186 in inhibiting cellular $\mathrm{Ca}^{2+}$ overload brought about by oxidative stress, in addition to the inhibitory effect on mitochondrial swelling and cytochrome c release [67].

$\mathrm{Ca}^{2+}$ channel blockers have been well studied in cardiac disease models, but the role of $\mathrm{MPTP}$ in relation to these blockers remains unclear. Ruthenium 360 is a specific $\mathrm{Ca}^{2+}$ uniport inhibitor, which reduces mitochondrial $\mathrm{Ca}^{2+}$ by blocking $\mathrm{mPTP}$ while not affecting $\mathrm{Ca}^{2+}$ movement. This was associated with cardiac function recovery after ischemia [68]. Hearts adminis- tered with $\mathrm{Na}^{+} / \mathrm{H}^{+}$exchanger isoform 1 (NHE-1) inhibitors showed decreased muscle cell injury as evidenced by low lactate dehydrogenase release and improved cardiac function during reperfusion [69]. The NHE-1 inhibitor cariporide was also able to mitigate oxidative stress-induced mitochondrial $\mathrm{Ca}^{2+}$ overload and mitochondrial membrane potential $(\Delta \Psi \mathrm{m})$ loss in neonatal cardiomyocytes [70]. Thus, there is a need to develop drugs that are more potent in targeting other aspects of $\mathrm{mPTP}$, without disrupting normal mitochondrial function.

\section{FUTURE DIRECTION AND CONCLUSION}

Mitochondria are deemed pivotal in both normal and pathological functioning of the heart, and are implicated as either the primary cause or an aid in the progression of HF. There are many other factors that are yet to be considered in order to come up with more successful methods of dealing with HF. Pharmacological intervention may be used in patients at the risk of HF, especially when addressing novel cardiac targets such as mitochondrial PTM [71]. Briefly, PTMs are conformational changes that occur in a protein after the translational process, in response to external stimuli like ROS or aberrant signaling, and these PTMs significantly affect cellular function [7].

Taken together, maintaining mitochondrial biogenesis against cardiac injury and decreasing mitochondrial ROS are two promising mechanisms that may lead to effective treatments for HF. In addition, results from experiments show that MPTP also holds promise as a target in HF treatment; these experiments should be followed up.

\section{REFERENCES}

1. Bui AL, Horwich TB, Fonarow GC. Epidemiology and risk profile of heart failure. Nat Rev Cardiol 2011;8:30-41.

2. Levy D, Kenchaiah S, Larson MG, Benjamin EJ, Kupka MJ, Ho KK, et al. Long-term trends in the incidence of and survival with heart failure. N Engl J Med 2002;347:1397-402.

3. Sowers JR, Epstein M, Frohlich ED. Diabetes, hypertension, and cardiovascular disease: an update. Hypertension 2001;37:1053-9.

4. Gheorghiade M, Sopko G, De Luca L, Velazquez EJ, Parker JD, Binkley PF, et al. Navigating the crossroads of coronary artery disease and heart failure. Circulation 2006;114:1202-13.

5. Chen HM, Lin CC, Kang CS, Lee CT, Lin HC, Chung SD. Bladder pain syndrome/interstitial cystitis increase the risk of coronary heart disease. Neurourol Urodyn 2014;33:511-5. 
6. Kuzmicic J, Del Campo A, Lopez-Crisosto C, Morales PE, Pennanen C, Bravo-Sagua R, et al. Mitochondrial dynamics: a potential new therapeutic target for heart failure. Rev Esp Cardiol 2011;64:916-23.

7. Marquez J, Lee SR, Kim N, Han J. Post-translational modifications of cardiac mitochondrial proteins in cardiovascular disease: not lost in translation. Korean Circ J 2016;46:1-12.

8. Doenst T, Nguyen TD, Abel ED. Cardiac metabolism in heart failure: implications beyond ATP production. Circ Res 2013;113:70924.

9. Witt H, Schubert C, Jaekel J, Fliegner D, Penkalla A, Tiemann K, et al. Sex-specific pathways in early cardiac response to pressure overload in mice. J Mol Med (Berl) 2008;86:1013-24.

10. Faerber G, Barreto-Perreia F, Schoepe M, Gilsbach R, Schrepper A, Schwarzer M, et al. Induction of heart failure by minimally invasive aortic constriction in mice: reduced peroxisome proliferator-activated receptor $\gamma$ coactivator levels and mitochondrial dysfunction. J Thorac Cardiovasc Surg 2011;141:492-500, 500.e1.

11. Sebastiani M, Giordano C, Nediani C, Travaglini C, Borchi E, Zani $\mathrm{M}$, et al. Induction of mitochondrial biogenesis is a maladaptive mechanism in mitochondrial cardiomyopathies. J Am Coll Cardiol 2007;50:1362-9.

12. Lee SR, Kim N, Noh Y, Xu Z, Ko KS, Rhee BD, et al. Mitochondrial DNA, mitochondrial dysfunction, and cardiac manifestations. Front Biosci (Landmark Ed) 2016;21:1410-26.

13. Sun CK, Chang LT, Sheu JJ, Wang CY, Youssef AA, Wu CJ, et al. Losartan preserves integrity of cardiac gap junctions and PGC-1 alpha gene expression and prevents cellular apoptosis in remote area of left ventricular myocardium following acute myocardial infarction. Int Heart J 2007;48:533-46.

14. Garnier A, Fortin D, Delomenie C, Momken I, Veksler V, VenturaClapier R. Depressed mitochondrial transcription factors and oxidative capacity in rat failing cardiac and skeletal muscles. J Physiol 2003;551(Pt 2):491-501.

15. Li H, Wang J, Wilhelmsson H, Hansson A, Thoren P, Duffy J, et al. Genetic modification of survival in tissue-specific knockout mice with mitochondrial cardiomyopathy. Proc Natl Acad Sci U S A 2000;97:3467-72.

16. Wang J, Wilhelmsson H, Graff C, Li H, Oldfors A, Rustin P, et al. Dilated cardiomyopathy and atrioventricular conduction blocks induced by heart-specific inactivation of mitochondrial DNA gene expression. Nat Genet 1999;21:133-7.

17. Moens AL, Ketner EA, Takimoto E, Schmidt TS, O’Neill CA, Wolin MS, et al. Bi-modal dose-dependent cardiac response to tetrahydrobiopterin in pressure-overload induced hypertrophy and heart failure. J Mol Cell Cardiol 2011;51:564-9.

18. Graham BH, Waymire KG, Cottrell B, Trounce IA, MacGregor GR, Wallace DC. A mouse model for mitochondrial myopathy and cardiomyopathy resulting from a deficiency in the heart/muscle isoform of the adenine nucleotide translocator. Nat Genet 1997;16:22634.

19. Li Y, Huang TT, Carlson EJ, Melov S, Ursell PC, Olson JL, et al. Dilated cardiomyopathy and neonatal lethality in mutant mice lacking manganese superoxide dismutase. Nat Genet 1995;11:376-81.

20. Hansson A, Hance N, Dufour E, Rantanen A, Hultenby K, Clayton $\mathrm{DA}$, et al. A switch in metabolism precedes increased mitochondrial biogenesis in respiratory chain-deficient mouse hearts. Proc Natl Acad Sci U S A 2004;101:3136-41.

21. Rosca MG, Hoppel CL. Mitochondrial dysfunction in heart failure. Heart Fail Rev 2013;18:607-22.

22. Cai Y, Zhao L, Qin Y, Wu XQ. EGCG blocked phenylephrin-induced hypertrophy in $\mathrm{H} 9 \mathrm{C} 2$ cardiomyocytes, by activating AMPKdependent pathway. Korean J Physiol Pharmacol 2015;19:203-10.

23. Duncker DJ, van Deel ED. Endothelial nitric oxide synthase and cardiac remodelling: location, location, location0? Cardiovasc Res 2012;93:383-5.

24. Yanagishita T, Tomita M, Itoh S, Mukae S, Arata H, Ishioka H, et al. Protective effect of captopril on ischemic myocardium. Jpn Circ J 1997;61:161-9.

25. Sun W, Zhang H, Guo J, Zhang X, Zhang L, Li C, et al. Comparison of the efficacy and safety of different ACE inhibitors in patients with chronic heart failure: a PRISMA-compliant network metaanalysis. Medicine (Baltimore) 2016;95:e2554.

26. Lai YC, Tabima DM, Dube JJ, Hughan KS, Vanderpool RR, Goncharov DA, et al. SIRT3-AMP-activated protein kinase activation by nitrite and metformin improves hyperglycemia and normalizes pulmonary hypertension associated with heart failure with preserved ejection fraction. Circulation 2016;133:717-31.

27. Benes J, Kazdova L, Drahota Z, Houstek J, Medrikova D, Kopecky J, et al. Effect of metformin therapy on cardiac function and survival in a volume-overload model of heart failure in rats. Clin Sci (Lond) 2011;121:29-41.

28. Yin M, van der Horst IC, van Melle JP, Qian C, van Gilst WH, Sillje $\mathrm{HH}$, et al. Metformin improves cardiac function in a nondiabetic rat model of post-MI heart failure. Am J Physiol Heart Circ Physiol 2011;301:H459-68.

29. Gundewar S, Calvert JW, Jha S, Toedt-Pingel I, Ji SY, Nunez D, et al. Activation of AMP-activated protein kinase by metformin improves left ventricular function and survival in heart failure. Circ Res 2009;104:403-11. 
30. Suematsu Y, Miura SI, Goto M, Matsuo Y, Arimura T, Kuwano T, et al. LCZ696, an angiotensin receptor-neprilysin inhibitor, improves cardiac function with the attenuation of fibrosis in heart failure with reduced ejection fraction in streptozotocin-induced diabetic mice. Eur J Heart Fail 2016 Jan 7 [Epub]. Http://dx.doi.org/10.1002/ejhf.474.

31. Solomon SD, Claggett B, Desai AS, Packer M, Zile M, Swedberg K, et al. Influence of ejection fraction on outcomes and efficacy of sacubitril/valsartan (LCZ696) in heart failure with reduced ejection fraction: the prospective comparison of ARNI with ACEI to determine impact on global mortality and morbidity in heart failure (PARADIGM-HF) trial. Circ Heart Fail 2016;9:e002744.

32. Yao K, Zhang WW, Yao L, Yang S, Nie W, Huang F. Carvedilol promotes mitochondrial biogenesis by regulating the PGC-1/TFAM pathway in human umbilical vein endothelial cells (HUVECs). Biochem Biophys Res Commun 2016;470:961-6.

33. DeVore AD, Mi X, Mentz RJ, Fonarow GC, Van Dyke MK, Maya JF, et al. Discharge heart rate and $\beta$-blocker dose in patients hospitalized with heart failure: findings from the OPTIMIZE-HF registry. Am Heart J 2016;173:172-8.

34. De Toni L, Strapazzon G, Gianesello L, Caretta N, Pilon C, Bruttocao A, et al. Effects of type 5-phosphodiesterase inhibition on energy metabolism and mitochondrial biogenesis in human adipose tissue ex vivo. J Endocrinol Invest 2011;34:738-41.

35. Schwartz BG, Levine LA, Comstock G, Stecher VJ, Kloner RA. Cardiac uses of phosphodiesterase-5 inhibitors. J Am Coll Cardiol 2012;59:9-15.

36. Moens AL, Takimoto E, Tocchetti CG, Chakir K, Bedja D, Cormaci $G$, et al. Reversal of cardiac hypertrophy and fibrosis from pressure overload by tetrahydrobiopterin: efficacy of recoupling nitric oxide synthase as a therapeutic strategy. Circulation 2008;117:2626-36.

37. Chong E, Chang SL, Hsiao YW, Singhal R, Liu SH, Leha T, et al. Resveratrol, a red wine antioxidant, reduces atrial fibrillation susceptibility in the failing heart by PI3K/AKT/eNOS signaling pathway activation. Heart Rhythm 2015;12:1046-56.

38. Biala A, Tauriainen E, Siltanen A, Shi J, Merasto S, Louhelainen M, et al. Resveratrol induces mitochondrial biogenesis and ameliorates Ang II-induced cardiac remodeling in transgenic rats harboring human renin and angiotensinogen genes. Blood Press 2010;19:196205.

39. Hafstad AD, Nabeebaccus AA, Shah AM. Novel aspects of ROS signalling in heart failure. Basic Res Cardiol 2013;108:359.

40. Burgoyne JR, Mongue-Din H, Eaton P, Shah AM. Redox signaling in cardiac physiology and pathology. Circ Res 2012;111:1091-106.

41. Tsutsui H, Kinugawa S, Matsushima S. Oxidative stress and mitochondrial DNA damage in heart failure. Circ J 2008;72 Suppl A:A31-
7.

42. Olsen RK, Cornelius N, Gregersen N. Redox signalling and mitochondrial stress responses; lessons from inborn errors of metabolism. J Inherit Metab Dis 2015;38:703-19.

43. Lu Z, Xu X, Hu X, Fassett J, Zhu G, Tao Y, et al. PGC-1 alpha regulates expression of myocardial mitochondrial antioxidants and myocardial oxidative stress after chronic systolic overload. Antioxid Redox Signal 2010;13:1011-22.

44. Bayeva M, Ardehali H. Mitochondrial dysfunction and oxidative damage to sarcomeric proteins. Curr Hypertens Rep 2010;12:42632.

45. Kwon SH, Pimentel DR, Remondino A, Sawyer DB, Colucci WS. $\mathrm{H}(2) \mathrm{O}(2)$ regulates cardiac myocyte phenotype via concentrationdependent activation of distinct kinase pathways. J Mol Cell Cardiol 2003;35:615-21.

46. Siwik DA, Colucci WS. Regulation of matrix metalloproteinases by cytokines and reactive oxygen/nitrogen species in the myocardium. Heart Fail Rev 2004;9:43-51.

47. Goyal BR, Mehta AA. Beneficial role of spironolactone, telmisartan and their combination on isoproterenol-induced cardiac hypertrophy. Acta Cardiol 2012;67:203-11.

48. Dizon LA, Seo DY, Kim HK, Kim N, Ko KS, Rhee BD, et al. Exercise perspective on common cardiac medications. Integr Med Res 2013;2:49-55.

49. Davogustto G, Taegtmeyer H. Perhexiline, Cardiac energetics, and heart failure: lessons from the first law of thermodynamics. JACC Heart Fail 2015;3:659-60.

50. Zorov DB, Juhaszova M, Sollott SJ. Mitochondrial reactive oxygen species (ROS) and ROS-induced ROS release. Physiol Rev 2014;94: 909-50.

51. Williams GS, Boyman L, Lederer WJ. Mitochondrial calcium and the regulation of metabolism in the heart. J Mol Cell Cardiol 2015; 78:35-45.

52. Brustovetsky N, Klingenberg M. Mitochondrial ADP/ATP carrier can be reversibly converted into a large channel by $\mathrm{Ca}^{2+}$. Biochemistry 1996;35:8483-8.

53. Baines CP, Kaiser RA, Sheiko T, Craigen WJ, Molkentin JD. Voltage-dependent anion channels are dispensable for mitochondrialdependent cell death. Nat Cell Biol 2007;9:550-5.

54. Leung AW, Varanyuwatana P, Halestrap AP. The mitochondrial phosphate carrier interacts with cyclophilin D and may play a key role in the permeability transition. J Biol Chem 2008;283:26312-23. 55. Solesio ME, Elustondo PA, Zakharian E, Pavlov EV. Inorganic polyphosphate (polyP) as an activator and structural component of the mitochondrial permeability transition pore. Biochem Soc Trans 
2016;44:7-12.

56. Nazareth W, Yafei N, Crompton M. Inhibition of anoxia-induced injury in heart myocytes by cyclosporin A. J Mol Cell Cardiol 1991;23:1351-4.

57. Griffiths EJ, Halestrap AP. Protection by cyclosporin A of ischemia/ reperfusion-induced damage in isolated rat hearts. J Mol Cell Cardiol 1993;25:1461-9.

58. Nakagawa T, Shimizu S, Watanabe T, Yamaguchi O, Otsu K, Yamagata $\mathrm{H}$, et al. Cyclophilin D-dependent mitochondrial permeability transition regulates some necrotic but not apoptotic cell death. Nature 2005;434:652-8.

59. Periasamy M. Calcineurin and the heartbeat, an evolving story. J Mol Cell Cardiol 2002;34:259-62.

60. Schreiber SL, Crabtree GR. The mechanism of action of cyclosporin A and FK506. Immunol Today 1992;13:136-42.

61. Griffiths EJ, Halestrap AP. Mitochondrial non-specific pores remain closed during cardiac ischaemia, but open upon reperfusion. Biochem J 1995;307(Pt 1):93-8.

62. Argaud L, Gateau-Roesch O, Muntean D, Chalabreysse L, Loufouat J, Robert D, et al. Specific inhibition of the mitochondrial permeability transition prevents lethal reperfusion injury. J Mol Cell Cardiol 2005;38:367-74.

63. Gomez L, Thibault H, Gharib A, Dumont JM, Vuagniaux G, Scalfaro $P$, et al. Inhibition of mitochondrial permeability transition improves functional recovery and reduces mortality following acute myocardial infarction in mice. Am J Physiol Heart Circ Physiol 2007;293: H1654-61.

64. Clarke SJ, McStay GP, Halestrap AP. Sanglifehrin A acts as a potent inhibitor of the mitochondrial permeability transition and reperfu- sion injury of the heart by binding to cyclophilin-D at a different site from cyclosporin A. J Biol Chem 2002;277:34793-9.

65. Javadov SA, Lim KH, Kerr PM, Suleiman MS, Angelini GD, Halestrap AP. Protection of hearts from reperfusion injury by propofol is associated with inhibition of the mitochondrial permeability transition. Cardiovasc Res 2000;45:360-9.

66. Shao H, Li J, Zhou Y, Ge Z, Fan J, Shao Z, et al. Dose-dependent protective effect of propofol against mitochondrial dysfunction in ischaemic/reperfused rat heart: role of cardiolipin. $\mathrm{Br} J$ Pharmacol 2008;153:1641-9.

67. Rajesh KG, Sasaguri S, Suzuki R, Maeda H. Antioxidant MCI-186 inhibits mitochondrial permeability transition pore and upregulates Bcl-2 expression. Am J Physiol Heart Circ Physiol 2003;285: H2171-8.

68. Clements-Jewery H. Mitochondria, the calcium uniporter, and reperfusion-induced ventricular fibrillation. Br J Pharmacol 2006; 149: 811-3.

69. Javadov S, Choi A, Rajapurohitam V, Zeidan A, Basnakian AG, Karmazyn M. NHE-1 inhibition-induced cardioprotection against ischaemia/reperfusion is associated with attenuation of the mitochondrial permeability transition. Cardiovasc Res 2008;77:416-24.

70. Villa-Abrille MC, Cingolani E, Cingolani HE, Alvarez BV. Silencing of cardiac mitochondrial NHE1 prevents mitochondrial permeability transition pore opening. Am J Physiol Heart Circ Physiol 2011;300:H1237-51.

71. Liddy KA, White MY, Cordwell SJ. Functional decorations: posttranslational modifications and heart disease delineated by targeted proteomics. Genome Med 2013;5:20. 